\title{
Sosialisasi Dalam Mengelola Proses Pembelajaran Online di rumah pada Masa Pandemi Covid-19 Pada Siswa Kelas XII SMK Negeri 1 Karawang Yudi Firmansyah $^{1}$, Yogi Nugraha ${ }^{2}$, Asep Jamaludin ${ }^{3}$, Sihabudin ${ }^{4}$ Pendidikan Pancasila dan Kewarganegaraan, Fakultas Keguruan dan Ilmu Pendidikan Universitas Buana Perjuangan Karawang yudifirmansyah@ubpkarawang.ac.id yogi.nugraha@ubpkarawang.ac.id asepjamaludin@ubpkarawang.ac.id sihabudin@ubpkarawang.ac.id
}

\begin{abstract}
Ringkasan
Pengabdian ini dilatarbelakangi oleh perlunya adaptasi dalam hal mengelola proses pembelajaran tatap muka ke pembelajaran online yang dilakukan oleh guru dan siswa guna tetap dapat mengikuti perkembangan zaman dan meningkatkan kualitas pembelajaran di kelas. Adapun kegiatan ini akan dilakukan melalui zoom meeting dengan menggunakan metode sosialisasi. Sasaran dalam kegiatan ini adalah guru-guru di lingkungan SMKN 1 Karawang. Luaran pengabdian akan dipublikasikan di jurnal buana pengabdian UBP Karawang.

Kata Kunci : pengelolaan pembelajaran online, pandemic.
\end{abstract}

\section{Abstract}

This dedication is motivated by the need for adaptation in terms of managing the face-to-face learning process to online learning carried out by teachers and students in order to keep abreast of the times and improve the quality of learning in the classroom. This activity will be carried out through a zoom meeting using the socialization method. The targets in this activity are teachers in the SMKN 1 Karawang environment. The service output will be published in the UBP Karawang community service journal. Keywords: online learning management, pandemic.

\section{Pendahuluan}

Pengabdian kepada masyarakat merupakan salah satu Dharma seorang dosen dari Tri Dharma perguruan tinggi yang ada. Dharma ini harus dilaksanakan oleh segenap civitas akademika termasuk pengajar Universitas Buana Perjuangan. Sesuai dengan program yang telah dilaksanakan oleh Lembaga Penelitian dan Pengabdian pada Masyarakat (LPPM) Universitas Buana Perjuangan Karawang. Pelaksanaan pengabdian diprioritaskan sesuai dengan disiplin ilmu program studi Pendidikan Pancasila dan Kewarganegaraan, Maka pengabdi melaksanakan kegiatan pengabdian berupa Sosialisasi Dalam Mengelola Proses Pembelajaran Online di rumah pada Masa Pandemi Covid-19 Pada Siswa Kelas XII SMK Negeri 1 Karawang.

Belajar dari rumah tentu berbeda dengan kegiatan belajar di sekolah, selain adanya 
perangkat pembelajaran kegiatan belajar juga didukung oleh media belajar untuk memudahkan siswa dalam memahami materi. Menurut Indriana (2011: 15) media pembelajaran dimaksudkan merupakan salah satu alat komunikasi dalam proses pembelajaran, dikatakan demikian karena di dalam proses pembelajaran terdapat proses penyampaian pesan dari pendidik kepada anak didik. Media pembelajaran juga diartikan sebagai salah satu faktor eksternal yang berpengaruh terhadap keberhasilan kegiatan pembelajaran, secara umum manfaat media pembelajaran yakni untuk memperlancar interaksi anatar guru dengan siswa sehingga pembelajaran lebih efektif dan efisien (Numiek, 2013: 94-95).

Kegiatan belajar dari rumah akan membutuhkan media pembelajaran yang dibutuhkan siswa, agar siswa mudah memahami materi pelajaran. Pada kondisi ini akan sulit memberikan media pembelajaran karena orang tua kurang berpengalaman dalam mengajarkan anak materi dari sekolah dan siswa membutuhkan media pendukung sebagai sarana kelancaran belajar. Berdasarkan latar belakang di atas, pengabdi merasa terpanggil untuk membantu dan mensosialisasikan hasil penelitian tentang media-media pembelajaran inovatif yang telah dikembangkan oleh pengabdi. Dengan harapan pemahaman guru akan terbuka dan semakin semangat untuk meningkatkan kemampuan mereka dalam melaksanakan pembelajaran yang terus beradaptasi dengan teknologi.

\section{Metode}

Metode yang akan dilakukan dalam pengabdian pada masyarakat ini adalah dengan metode sosialisasi. Adapaun media yang digunakan adalah dengan menggunakan zoom meeting atau google meet. Hal ini dilakukan karena Kabupaten Karawang masih dalam kondisi yang tidak memungkinkan untuk melakukan kegiatan tatap muka secara langsung karena pandemi covid-19. Adapun langkah- langkah kegiatan Sosialisasi Dalam Mengelola Proses Pembelajaran Online di rumah pada Masa Pandemi Covid-19 dengan tahapan sebagai berikut:

1. Tahap persiapan dilakukan meliputi survey, pemantapan dan penentuan sasaran dengan menyusun bahan/materi sosialisasi tentang pengelolaan proses pembelajaran online di rumah.

2. Pelaksanaan kegiaatan pengabdian dilaksanakan pada tanggal 11 September 2021 kepada 
Yudi Firmansyah $^{1}$, Yogi Nugraha ${ }^{2}$, Asep Jamaludin ${ }^{3}$, Sihabudin ${ }^{4}$

Vol. 3 No 2, Agustus 2021

ISSN 2657-0203

e-ISSN 2686-0244

beberapa Guru dan Siswa kelas XII SMK Negeri 1 Karawang tentang pentingnya mengelola atau mengatur waktu proses pembelajaran secara mandiri tingkat SMA dan SMK Kabupaten Karawang.

\section{Hasil Pengabdian dan Pembahasan}

Tujuan dari pengabdian ini adalah untuk memberikan pemahaman kepada siswa dan guru dalam mengeloa pembelajaran selama masa pandemi. Pengelolaan kelas sendiri menurut Eliana (2010: 1) adalah suatu usaha yang dilakukan oleh penanggung jawab kegiatan pembelajaran dengan maksud agar tercapai kondisi optimal sehingga dapat terlaksana kegiatan belajar sebagaimana yang diharapkan. Dalam masa pandemi seperti sekarang pola pengelolaan poses pembelajaran harus diperhatikan dengan sekesama baik oleh Guru sebagai penetu dalam terlaksananya kegiatan pembelajaran dan siswa sebagai objek dalam proses pembelajaran itu sendiri. Menurut Guardia dan Syahiqul (2021) Indikator keberhasilan pengelolaan kelas sendiri antara lain: 1) Terciptanya lingkungan belajar yang kondusif, tertib, disiplin dan bergairah; 2) adanya hubungan yang baik antara siswa dan gurumaupun guru dan siswa secara interpersonal.

Setelah keluarnya Surat Edaran Mendikbud Nomor 36962/MPK/HK/2020 agar seluruh kegiatan belajar mengajar baik disekolah maupun perguruan tinggi menggunakan metode dalam jaringan (daring) atau online sebagai bentuk upaya pencegahan penularan Coronavirus disease (Covid-19) berdampak pada sulitnya para guru dan siswa dalam mengelola waktu untuk menyesuaikan pola belajar dari tatap muka menjadi dalam jaring (daring). System pembelajaran daring atau biasa disebut pembelajaran online adalah system pembelajaran tanpa tatap muka secara langsung oleh guru dan siswa melalui jaringan internet. Menurut Yudi Firmansyah dan Fani Kardina (2021) Pembelajaran dalam jaringan (online) disingkat sebagai pembelajaran Daring, pembelajaran online dengan memanfaatkan jaringan internet serta teknologi informasi untuk kegiatan interaksi antara guru dengan peserta didik, sehingga terjadi proses pembelajaran.

Dalam setiap proses pembelajaran setiap guru harus memastikan proses kegiatan pembelajaran tetap berlangsung dengan baik dengan mempersiapkan berbagai macam inovasi dengan memanfaatkan media daring (online). Berbagai macam media yang dapat digunakan antara lain WhatsApp (WA), telegram, instagram, google classroom, zoom meeting dan media lain yang mampu menunjang proses pembelajaran online tersebut dengan harapat siuswa dapat 
mengikuti. Selain guru, siswa juga mempunyai peranan utama dalam hal mengelola waktu pembelejaran sesuai dengan jadwal dan ketentuan-ketentuan yang diberikan oleh setiap guru. Karena banyak tugas, materi, diskusi yang mungkin diberikan oleh setiap guru mata pelajaran agar setiap kompetensi dasar mata pelajaran dapat tersampaikan dengan baik walapun proses pembelajarannya dilakukan secara daring.

\section{Kesimpulan}

Pandemi Covid-19 membuat pembelajaran secara tatap muka atau offline dihentikan untuk sementara waktu sampai keadaan membaik. Untuk mengatasi hal tersebut dipilihlah opsi untuk melakukan kegiatan pembelajaran secara daring atau biasa kita sebut dengan istilah online Pembelajaran daring merupakan pelaksanaan kegiatan belajar dan mengajar dengan menggunakan gadget yang tersambung dengan jaringan internet. Dalam setiap kegiatan pasti terdapat kendala, maka dari itu diperlukan penyesuaian dan rasa saling memahami antar komponen. Berdasarkan hasil pelaksanaan kegiatan pengabdian kepada masyarakat maka dapat disimpulkan kegiatan pelatihan Sosialisasi Dalam Mengelola Proses Pembelajaran Online di rumah pada Masa Pandemi Covid-19 dapat dilaksanakan dengan baik dan lancer.

\section{Referensi}

Dina Indriana. 2011. Ragam Alat Bantu Media Pengajaran. Yogyakarta: Diva Press.

Hanum, Numiek Sulistyo. 2013. Keefektifan E-learning Sebagai Media Pembelajaran (Studi Evaluasi Model Pembelajaran E-learning SMK Telkom Sandhy Putra Purwokerto). Jurnal Pendidikan Vokasi, Vol. 3, Nomor 1.

Rusman, dkk. 2011. Pembelajaran Berbasis Teknologi Informasi dan Komunikasi, Membangun Profesionalitas Guru. Jakarta: PT. Raja Grafindo.

Firmansyah, Yudi \& Kardina, Fani. (2020). Pengaruh New Normal di tengah Pandemi Covid-19 Terhadap Pengelolahan Sekolah dan Peserta Didik. Jurnal Buana Ilmu. 4 (2). http://journal.ubpkarawang.ac.id/index.php/BuanaIlmu/article/view/1107

Mulyasidhi, Guardia \& Syahidul Haq, Mohammad (2021. Manajemen Kelas Dalam Kegiatan Pembelajaran Bagi Siswa Sekolah Dasar Pada Masa Pandemi Covid-19. Jurnal Inspirasi Manajemen pendidikan. Vol 9 No 1. https://ejournal.unesa.ac.id/index.php/inspirasimanajemenpendidikan/article/view/38584 